\title{
The Best Hot Water Strategy for Bathtub
}

\author{
Haoming Guo 1, a \\ 1 North China Electric Power University, Beijing 102206, China \\ a738800271@qq.com
}

Keywords: Heat distribution, Finite-Element Analysis, PDE

Abstract. Through the analysis of the heat distribution inside the bathtub affected by different tempe ratures. The paper finds that the best strategy the person in the bathtub can adopt to keep the temperature even throughout the bathtub and as close as possible to the initial temperature without wasting too much water. Furthermore, according to the requirements given by the problem, the authors propose a evaluation method to determine the extent to which the strategy depends upon given factors.

The paper proposes one model and one algorithm. The model can be used to find the best strategy of bathtub problem. In the analysis of this model, according to the questions given by the problem, we proposed two main factors: quality of heating water and different ways of adding hot water. Then, th e paper analyzes the changing speed of bathtub water as hot water added in two different ways, addi ng heat flux density $\mathrm{Q}$ and specific heat capacity of water $\mathrm{C}$ in order to construct energy conservatio $\mathrm{n}$ equation. Then, we proposed two ways of adding hot water as the best strategy in response to the $\mathrm{c}$ ondition given by the problem.

For the first way of adding hot water continuously, PDE and CFD simulation are adopted to model $t$ he temperature of the bathtub water in space and time; for the other way of adding hot water at regul ar intervals, we use energy conservation equation and Recursive Computation of Space Multibody Dynamics, to develop a model in space and time. By comparing these two ways, we get the best stra tegy the person in the bathtub can adopt to keep the temperature even throughout the bathtub and as close as possible to the initial temperature without wasting too much water.

Multiple linear regression equation is used to determine the extent to which our strategy depends up on given factors. These factors can also affect the heat conduction, heat convection and heat radiatio $\mathrm{n}$ which are taken into consideration in energy conservation equation.

\section{Introduction}

With the development of the ages, people pay greater attention to the comfort when they are using a bathtub. When we settle into a bathtub which is not a spa-style tub with a secondary heating system and circulating jets, but rather a simple water containment vessel, we have to add a constant trickle of hot water from the faucet to reheat the bathing water. However, the lack of water is likewise a serious problem. So how can we use the bath water as little as possible when we bathing become a critical question. We should consider how to balance the water temperature and water consumption, when we seek the minimum of water consumption.Meanwhile, using a bubble bath additive will also affect water consumption and water temperature, so it is also considered in our paper.

\section{Assumptions}

The bathtub is made by the most common material: acrylic.

The initial situation is a man in the bathtub which is filled with water with appropriate temperature. The volume of bathtub is V1, the volume of man is V2, the volume of man's body is Vp1(surrounded the water), the volume of man's body is Vp2(surrounded by the air).

Because water has high specific heat capacity, we assume that water is a kind of poor conductor of heat, water transfer heat by convection.

\section{Model}

A.Situation 1:Hot water is discontinuously added into bathtub.

The temperature of the liquid mixture according to the formula: $Q=c m \Delta T$

Where $\mathrm{c}$ is the specific heat coefficient, $\mathrm{m}$ is quality, $\Delta \mathrm{T}$ is temperature difference. We assume the quality of water in the bathtub is $\mathrm{M} \mathrm{kg}$ and water temperature is T0.Adding hot water $\mathrm{m} 1 \mathrm{~kg}$ per unit time and the water temperature is Ta.Flowing out water $m 2 \mathrm{~kg}$ per unit time and the water temperature is T0.After adding hot water, the hybrid temperature is T. 
Table1.The feature of Specific heat capacity model

\begin{tabular}{|c|c|c|c|c|}
\hline \multirow{2}{*}{ Frequency } & \multicolumn{2}{|c|}{ The initial state } & \multicolumn{2}{c|}{ Adding water } \\
\cline { 2 - 5 } & Water & Temperature & Water & Temperature \\
\hline 1 & $\mathrm{M}$ & $T_{0}$ & $m_{1}$ & $T_{a}$ \\
\hline 2 & $\mathrm{M}$ & $\frac{m_{1} T_{a}+\left(M+m_{1}+m_{2}\right) T_{0}}{M+2 m_{1}+m_{2}}$ & $\begin{array}{r}m^{2} \\
1\end{array}$ & $T_{a}$ \\
\hline \hline \multirow{2}{*}{ Frequency } & \multicolumn{2}{|c|}{ Flowing out water } & & The hybrid temperature \\
\cline { 2 - 3 } & Water & Temperature & & $\frac{m_{1} T_{a}+\left(M+m_{1}+m_{2}\right) T_{0}}{M+2 m_{1}+m_{2}}$ \\
\hline \multirow{2}{*}{1} & $m_{2}$ & $T_{0}$ & $\frac{m_{1} T_{a}+\left(M+m_{1}+m_{2}\right) \frac{m_{1} T_{a}+\left(M+m_{1}+m_{2}\right)}{M+2 m_{1}+m_{2}}}{M+2 m_{1}+m_{2}}$ \\
\hline
\end{tabular}

After cooling for some time, adding $\mathrm{m} 1$ hot water whose temperature is Ta into bathtub.This model is based on specific heat capacity of the fluid, so we didn't consider heating time and other heat transfer. Thus, after adding hot water, the temperature of the total water is $\mathrm{T} 1$

$$
\left\{\begin{array}{l}
T_{1}=\frac{m_{1} T_{a}+\left(M+m_{1}+m_{2}\right) T_{0}}{M+2 m_{1}+m_{2}}-T_{0} \\
Q_{i n}=C M\left(T_{1}-T_{0}\right)
\end{array}\right.
$$

When the man stops adding hot water, the bathtub water temperature is decreasing.

During the process of temperature decreasing, equivalent resistance is Ri, it relates to the shape and volume of the bathtub. Convective heat transfer coefficient between the tub wall and indoor air is h2, contact area of water and man is A, Convective heat transfer coefficient between water and indoor air is h3.

$$
\left\{\begin{array}{l}
R_{1}=\frac{2 L(H+W)}{\delta} \\
R_{2}=\frac{1}{A h_{2}} \\
R_{3}=\frac{1}{A h_{3}}
\end{array}\right.
$$$$
Q_{\text {out }}=\Delta \tau\left[\frac{T_{1}-T_{0}}{\sum_{i=1}^{3} R_{i}}+\beta\left(P_{a}^{\prime \prime}-P_{a}\right) A_{3}+o(n)\right]
$$

According to energy conservation law, water consumption per unit of time:

$$
m=\frac{m_{1}}{\Delta \tau}=\frac{m_{1}\left[\frac{T_{1}-T_{0}}{\sum_{i=1}^{3} R_{i}}+\beta\left(P_{a}^{\prime \prime}-P_{a}\right) A_{3}+O(n)\right]}{C M\left(T_{1}-T_{0}\right)}
$$

So, we concluded that $\sum_{i=1}^{3} R_{i}$ relate to shape and volume of the bathtub.

B. Situation 2:Hot water is consecutively added into bathtub

With respect to the temperature of the bathtub water, we ignore the radiating of water.The initial temperature of bathtub water isf $(0)=\mathrm{T} 0$ According to the specific heat capacity formula, we obtain the relationship of bathtub water temperature between $\tau$ and $\tau+1$.

$$
C m_{1}\left[T_{a}-f(\tau+1)\right]=C\left(M+m_{1}+m_{2}\right)[f(\tau+1)-f(\tau)]
$$


We can derive the expression by calculation we obtain:

$$
f(\tau)=\frac{1-k_{2}^{\tau}}{1-k_{2}}\left[k_{1}+\left(k_{2}-1\right) T_{0}\right]+T_{0} \quad k_{1}=\frac{m_{1} T_{a}}{M+2 m_{1}+m_{2}} \quad k_{2}=\frac{M+m_{1}+m_{2}}{M+2 m_{1}+m_{2}}
$$

We need $\min (\mathrm{m} 1 \tau) \quad$ st:f( $\tau)-\mathrm{T} 0$ approach to 0 .

D. Algorithm and simulation

Using the above equations by an iterative algorithm, we can simulate the transformation of bathtub water under the different conditions. Considering the effect of environmental factors, we assume a specific situation, part of eigenvalues are as follows:

Table2.Parameters of standard state

\begin{tabular}{ll}
\hline$h \lambda$ & $0.635\left[\mathrm{~W} / \mathrm{Km}^{2}\right]$ \\
$\mathrm{C}$ & $4200\left[\mathrm{~J} / \mathrm{kg}^{\circ} \mathrm{C}\right]$ \\
$h r$ & $3.45\left[\mathrm{~W} / \mathrm{Km}^{2}\right]$ \\
$S r$ & $0.036\left[\mathrm{~m}^{2}\right]$ \\
$\mathrm{D}$ & $0.05\left[\mathrm{~m}^{2}\right]$ \\
$h r d$ & $1000-12000\left[\mathrm{~W} / \mathrm{Km}^{2}\right]$ \\
\hline
\end{tabular}

The $h \lambda$ represents equivalent convective heat transfer coefficient of water surface; the $C$ represents the specific heat capacity of water; the $\mathrm{hr}$ represents convective heat transfer coefficient between tub wall and the air; the $\mathrm{Sr}$ represents the surface area of man in the bathtub; the D represents thickness of bathtub; the hrd represents the convective heat trans-fer coefficient when people in the disturbance.

Multivariate linear regression model:

$V i w=\left[\beta_{0}, \beta_{1}, \beta_{2}, \beta_{3}, \beta_{4}, \beta_{5}, \beta_{6}, \beta_{7}, \beta_{8}, \beta_{9}, \beta_{10}, \beta_{11}\right] *[1, H, H d r, L, T b, T d, T i, t i w, V p, V w, W, T r]^{\mathrm{T}}$

According the above equation and temperature model in model 2, we based on implicit difference format of multi-grid algorithm, simulating and analyzing 1000 groups of data. We discuss and analyze the 12 groups of different variables. Finally we get some data(detailed in Appendix). Depending on multiple linear regression, we measure the variables' dependent degree of the model, it decide the dependent degree of our model's variables. We use MATLAB to standard regression analysis process data and obtain the prelimi-nary residual plots.

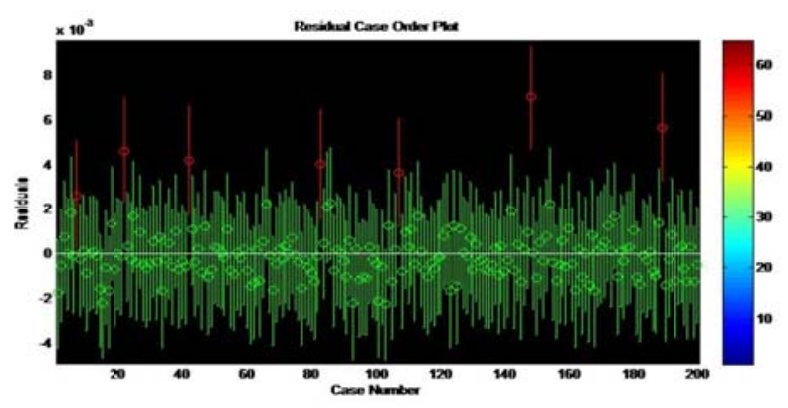

F ig. 1 Residual plots

After excluding outliers, regressing models again, we get improved models: 
Table3

\begin{tabular}{|c|c|c|}
\hline Regression coeffcients & Regression coeffcient estimates & Regression coeffcient confidence interval \\
\hline $\begin{array}{l}P_{0} \\
0\end{array}$ & 0.0125 & {$[-0.0209,0.0458]$} \\
\hline $\begin{array}{r}P_{1} \\
\end{array}$ & -1.8722 & {$[-3.8587,0.1144]$} \\
\hline$\beta_{2}$ & 0.5513 & {$[0.4163,0.6863]$} \\
\hline $\begin{array}{r}P_{3} \\
\end{array}$ & -1.6359 & {$[-3.8283,0.5566]$} \\
\hline$\beta_{4}$ & 1.1011 & {$[1.0142,1.1879]$} \\
\hline$\beta_{5}$ & 11.6181 & {$[6.3935,16.8427]$} \\
\hline$\beta_{6}$ & -4.3589 & {$[-5.8520,-2.8657]$} \\
\hline$\beta_{7}$ & 0.4916 & {$[0.1272,0.8561]$} \\
\hline$\beta_{8}$ & 0.2973 & {$[0.0946,0.5000]$} \\
\hline$\beta_{9}$ & 0.7534 & {$[-0.6871,2.1939]$} \\
\hline$P_{10}$ & 0 & 0 \\
\hline$p_{11}$ & -8.4366 & {$[-12.9639,-3.9092]$} \\
\hline
\end{tabular}

We deal with data by sub-standard treatment, then the regression equation is called standard regression equation. $\quad V i w=(-1.952) * H+0.4569 * H d r+(-1.4205) * L+1.0213 * T b+11.5696 * T d+(-4.5245)$ $* T i+0.502 * t i w+0.2546 * V p+0.5246 * V w+(-8.7747) * T r$

Through the analysis of two water adding processwe found that if the water has been added to the water, the water temperature must remain above the initial temperature. This will produce more heat per unit of time, so that can not achieve the purpose of saving wa-ter.On the basis of our hypothesis, the heating mode of the water discharge is more than the amount of water produced by the unit time of the intermittent discharge of water, $0.0 .2 \mathrm{~L}$. So continuous water is not an optimal strategy. The another situation of adding hot water, causing the rang of human body's comfortable temperature,so we can achieve the best strategy as long as we can add water in the human body's comfortable temperature. In the standard linear regression equation, we can see that the water consumption per unit of time $(\mathrm{m})$ and the lowest bath water temperature (Ti) and bath volume $(\mathrm{V})$ and hot water unit of time(T) are in a great relationship. So under our assumptions ,in order to minimum water consumption per unit time, we can make it as close as possible to the initial temperature of water, with the water temperature in the bath being fluctuate within the range of the initial temperature.

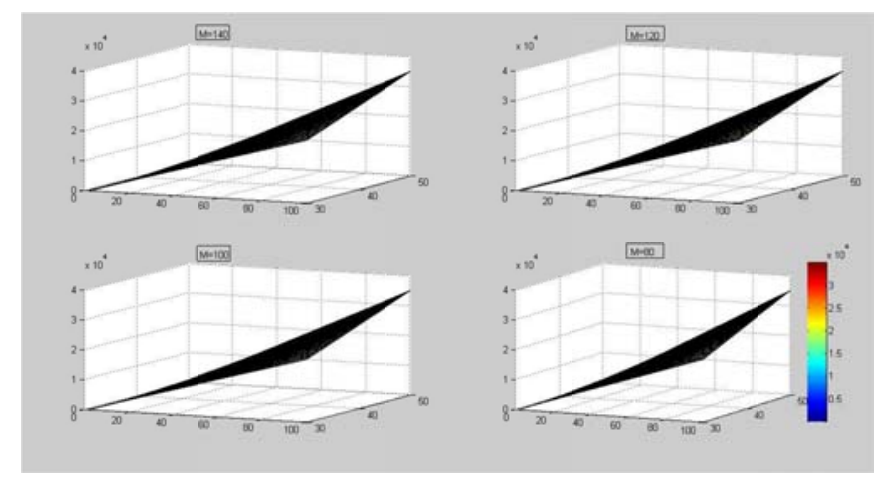

$F$ ig. 2 olume of water $T$ emperature $T$ ime

The relationship between $\mathrm{M}$ and $\mathrm{m}$. When $\mathrm{M}$ changes , based on this assumption, ignore other factors. This picture Indicate the degree of dependence between $\mathrm{M}$ and $\mathrm{m}$. It is close to the result above.So, The error of simulation process is very small. 
E. The best strategy

\begin{tabular}{c|c|c|c|c|c|c|c|c}
\multicolumn{1}{c}{ Table4 } \\
Time $($ minutes $)$ & 25 & 30 & 35 & 40 & 45 & 50 & 55 & 60 \\
\hline Temperature $\left({ }^{\circ} \mathrm{C}\right)$ & $38.9^{\circ} \mathrm{C}$ & $38.4^{\circ} \mathrm{C}$ & $37.9^{\circ} \mathrm{C}$ & $37.4^{\circ} \mathrm{C}$ & $38.4^{\circ} \mathrm{C}$ & $38^{\circ} \mathrm{C}$ & $37.7^{\circ} \mathrm{C}$ & $37.4^{\circ} \mathrm{C}$ \\
\hline $\operatorname{Volume}\left(m^{3}\right)$ & 0.038 & 0.044 & 0.049 & 0.053 & 0.087 & 0.096 & 0.103 & 1.109
\end{tabular}

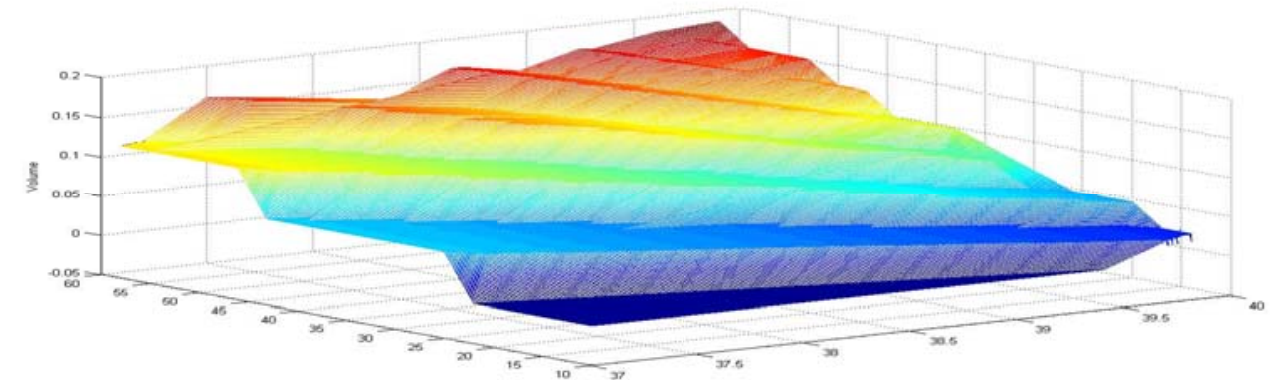

F ig. $3 \mathrm{~V}$ olume of water $\mathrm{T}$ emperature Time

We simulate 1200 groups of data in the normal situation 1 and learn the relationship between temperature lower limit, bath time and water consumption by multiple linear re-gression analysis. We get the 3D simulation image by three-dimensional interpolation and finally find out our best strategy correspond different bath time. In different bath time, we set up different temperature lower limit, so that we can use the corresponding lowest water consumption. For example, if you spend 30 minutes bathing, adding hot water when the temperature at $38.4{ }^{\circ} \mathrm{C}$ is the best way to avoid wasting more water, you just need $0.044 \mathrm{~m} 3$ water. Absolutely, if your bath time is under 25 minutes, the lower temperature limit makes the lower water consumption. Implementing this strategy, user can get the best feeling, meanwhile saving lots of water.

The other situation is the user only wants to use a bathtub to relax, at this moment the temperature is the most important factor. There is no doubt that the user will consume more water to keep the bathtub temperature as close as the initial temperature. In this situation, we suggest users stop bathing when the temperature of the bathtub water approach to temperature limit, in other words, you can stop adding hot water in advance. In this way, you can enjoy your bath time to the utmost extent.

\section{References}

[1]Takezawa A, Yoon G H, Jeong S H, et al. Structural topology optimization with strength and heat conduction constraints [J]. Computer Methods in Applied Mechanics and Engineering, 2014, 276(7):341-361.

[2]Zhu B F. The equivalent heat conduction equation of pipe cooling in mass concrete considering influence of external temperature [J]. Journal of Hydraulic Engineering, 2003.

[3]Zhang Z M, Song Z T, Huang H Y. New Theory on Adiabatic Temperature Rise and Heat Conduction Equation of Concrete[J]. Journal of Hehai University, 2002, 30(3):1-6.

[4]Dems K, Rousselet B. Sensitivity analysis for transient heat conduction in a solid body Part II: Interface modification[J]. Structural and Multidisciplinary Optimization, 1999, 17(17):46-54.

[5]Nield D A. Estimation of the stagnant thermal conductivity of saturated porous me-dia[J]. International Journal of Heat and Mass Transfer, 1991, 34(6):1575-1576.

[6]Tajima M, Maki T, Katayama K. Study of heat transfer phenomena in quenching of steel. (3rd Report, Cooling curves during quenching and transient boiling heat transfer).[J]. Nihon Kikai Gakkai Ronbunshu B Hen/transactions of the Japan Society of Mechanical En-gineers Part B, 1988, 54(508):3491-3496.

[7]Aagardl R L, Bonne U, Matthys R J. Measurement of thermal conductivity and spe-cific heat: US, US4944035[P]. 1990. 